\title{
Mesoporous molecular sieve Sn-MCM-41 as Baeyer-Villiger oxidation catalyst for sterically demanding aromatic and $\alpha, \beta$-unsaturated aldehydes
}

\author{
Avelino Corma, * Sara Iborra, María Mifsud, and Michael Renz \\ Instituto de Tecnología Química, UPV-CSIC, Avda. los Naranjos, 46022 Valencia, Spain \\ E-mail: acorma@itq.upv.es
}

(received 11 Jan 05; accepted 16 Feb 05; published on the web 08 Mar 05)

\begin{abstract}
Sn-Beta is a successful Baeyer-Villiger oxidation catalyst for hydrogen peroxide, with a regular pore system with a 0.6 to $0.7 \mathrm{~nm}$ diameter. Diffusion of sterically more demanding substrates may be impeded, and therefore the mesoporous molecular sieve Sn-MCM-41 (channel diameter of $3.5 \mathrm{~nm}$ ) is reported here as an alternative catalyst for several substrates involving cyclocitral (6), safranal (10), myrtenal (14), cinnamaldehyde (18, X = H), para-methoxycinnamaldehyde $(\mathbf{1 8}, \mathrm{R}=\mathrm{OMe})$ and piperonal (22). The oxidation system Sn-MCM-41/hydrogen peroxide provides the Baeyer-Villiger oxidation product of all these $\alpha, \beta$-unsaturated- or aromatic aldehydes with excellent selectivities and conversions up to $90 \%$. Furthermore, except for cinnamaldehyde, the Sn-MCM-41 provides higher conversions than Sn-Beta — that can be attributed to the larger pore diameter and less to impediments to diffusion.
\end{abstract}

Keywords: $\alpha, \beta$-Unsaturated aldehyde, aromatic aldehyde, Baeyer-Villiger oxidation, heterogeneous catalysis, hydrogen peroxide, mesoporous tin-Lewis acid

\section{Introduction}

Sn-Beta has been reported to be an efficient catalyst for the Baeyer-Villiger oxidation with hydrogen peroxide in aqueous solution. ${ }^{1,2}$ In this, "green alternative", peracids are replaced by an aqueous hydrogen peroxide solution giving water as the sole by-product. An additional beneficial property of this chemoselective oxidation system is that isolated double bonds are not epoxidized. On the other hand, a desirable characteristic of the Baeyer-Villiger oxidation by peracids, namely the retention of configuration at a migrating asymmetric carbon atom, is also observed with the Sn-Beta zeolite/hydrogen peroxide oxidation system. This has been demonstrated in the asymmetric synthesis of $\delta$-decalactone (1, eq. 1$){ }^{3}$ an important component for cream and butter flavorings. ${ }^{4}$ The new oxidation systems involving their unique chemoselectivity allow alternative synthesis strategies. For instance, melonal (2,6-dimethyl-5- 
heptenal, 2) has been obtained by the Baeyer-Villiger oxidation of citral (3,7-dimethyl-6-octen1-al, 3) with subsequent saponification (Scheme 1, right hand side). ${ }^{5}$ Before, this compound was produced by a Darzens reaction with 6-methyl-5-hepten-2-one (4) with subsequent decarboxylation, making use of the halogenated reactive ethyl chloroacetate (5, cf. Scheme 1 , left-hand side). Having in mind that citral can be synthesized by aldol condensation of 6-methyl5-hepten-2-one (4, the starting material for the Darzens reaction) and acetaldehyde, the combination of this reaction with the Baeyer-Villiger oxidation by Sn-Beta/hydrogen peroxide may be considered as a halogen-free catalytic alternative for the Darzens reaction (Scheme 1).

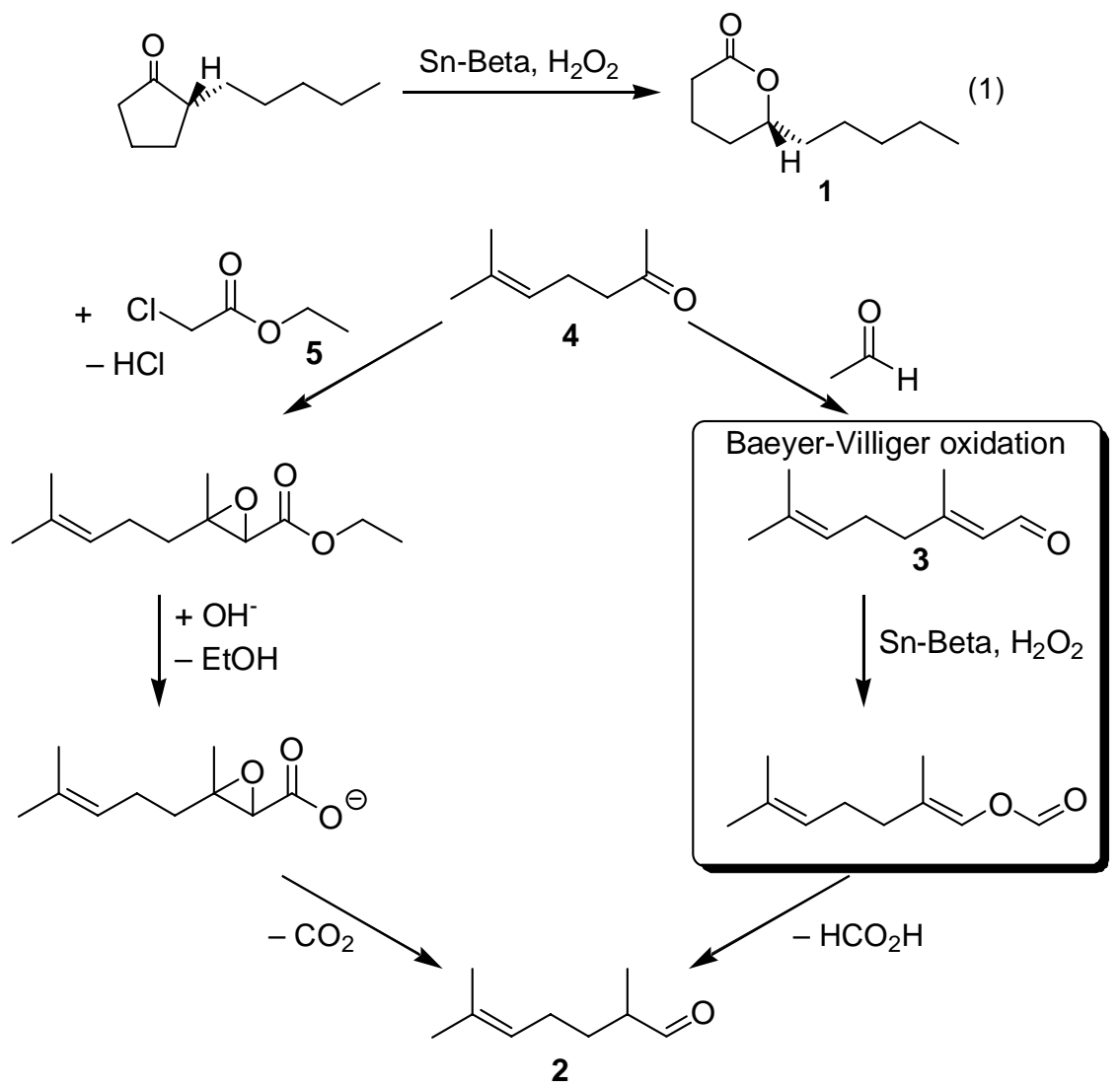

Scheme 1. Synthesis of melonal (2) from ketone 4, either by Darzens condensation with subsequent saponification and decarboxylation (left hand side) or by aldol condensation, BaeyerVilliger oxidation and saponification (right hand side).

When the Baeyer-Villiger oxidation involves large substrates ${ }^{6,7}$ Sn-Beta can become limited by the dimensions of the pores. To overcome this limitation we have introduced isolated $\mathrm{Sn}^{\mathrm{IV}}$ sites in the walls of a mesoporous molecular sieve with a pore diameter of approx. $3.5 \mathrm{~nm}$, namely MCM-41, resulting in an active and chemoselective catalyst for Baeyer-Villiger oxidations. ${ }^{5,8}$ Thus while citral (3) and melonal (2) are linear aldehydes that can diffuse well within the Beta pores, we will show here that for $\alpha, \beta$-unsaturated aldehydes with larger 
molecular size an Sn-containing mesoporous molecular sieve gives better performance than the microporous molecular sieve.

\section{Results and Discussion}

Citral can be cyclized to give cyclocitral (2,6,6-trimethyl-1-cyclohexene-1-carboxaldehyde, 6), which is also an $\alpha, \beta$-unsaturated aldehyde. When aldehyde 6 is oxidized by hydrogen peroxide in the presence of Sn-MCM-41 the corresponding formate ester 7 is obtained as the only product, with a conversion of $90 \%$ (Scheme 2). With Sn-Beta catalyst, its pore limitations become evident. Indeed, the conversion is only half of that achieved with Sn-MCM-41, and the regioselectivity for the Baeyer-Villiger is quite abnormal, the carboxylic acid 9 (hydrogen-atom migration product) being the main product. The Sn-MCM-41 catalyst can be collected after the reaction by filtration, and re-used without any special purification procedure. During three subsequent recycling runs the catalyst loses $10-15 \%$ of its activity, and which can be restored by a simple calcination at $500{ }^{\circ} \mathrm{C}$. Note that when meta-chloroperbenzoic acid is used as oxidant, the selectivity to the desired products (ester 7 and ketone 8 ) is only $55 \%$.

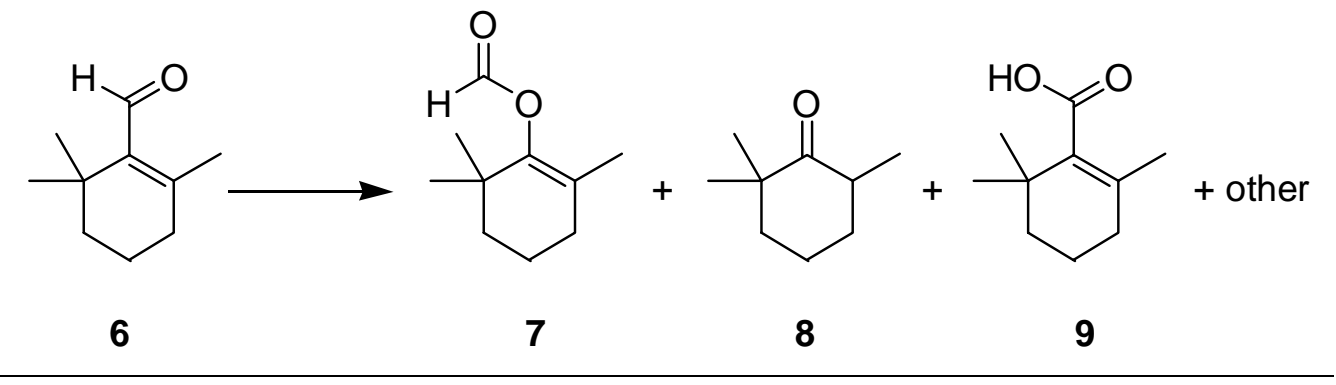

\begin{tabular}{cccccccccc}
\hline \multicolumn{1}{c}{ Conv. \% } & & & & & & & \\
\hline Sn-Beta & 43 & 33 & $:$ & 3 & $:$ & 64 & $:$ & 0 \\
Sn-MCM-41 & 90 & 100 & $:$ & 0 & $:$ & 0 & $:$ & 0 \\
$m$-CPBA & 62 & 52 & $:$ & 3 & $:$ & 0 & $:$ & 45 \\
\hline
\end{tabular}

Scheme 2. Product formation in the Baeyer-Villiger oxidation of aldehyde 6 . Reaction conditions: $0.5 \mathrm{~g}$ of aldehyde $6(3.7 \mathrm{mmol}), 1.5$ equiv. of aq. $\mathrm{H}_{2} \mathrm{O}_{2}(50 \%), 50 \mathrm{mg}$ of Sn-Beta, $3.0 \mathrm{~g}$ of tert.- amyl alcohol, at $100{ }^{\circ} \mathrm{C}$, for $1 \mathrm{~h}$. For the oxidation with $\mathrm{m}$-CPBA, $0.5 \mathrm{~g}$ of the aldehyde was reacted with 1.0 equiv. of $\mathrm{m}$-CPBA in $3.0 \mathrm{~g}$ of tert. Amyl alcohol at $100^{\circ} \mathrm{C}$ for $1 \mathrm{~h}$.

Safranal (10) is very similar to cyclocitral (6) but has an additional double bond in the $\gamma, \delta$ position. The corresponding Baeyer-Villiger oxidation product, 2,6,6-trimethyl-3-cyclohexen-1one (11), is an intermediate in the synthesis of $\beta$-damascenone. Again, a lower conversion was obtained with Sn-Beta than with Sn-MCM-41, probably owing to the slower diffusion of the 
safranal and the ester through the pores of Beta zeolite. This is supported by the fact that on SnMCM-41 with a pore diameter of $3.5 \mathrm{~nm}$ the reaction was even faster than that for the linear citral (3), and $68 \%$ of ester was obtained after $15 \mathrm{~min}$ reaction time, with practically $100 \%$ selectivity (Scheme 3). Peracids are completely unsuitable for the oxidation of safranal (10) since the desired Baeyer-Villiger products are only observed as minor products. Over-oxidation and other side-reactions consume the primary products, and lead to high-molecular- weight products after only $1 \mathrm{~h}$.

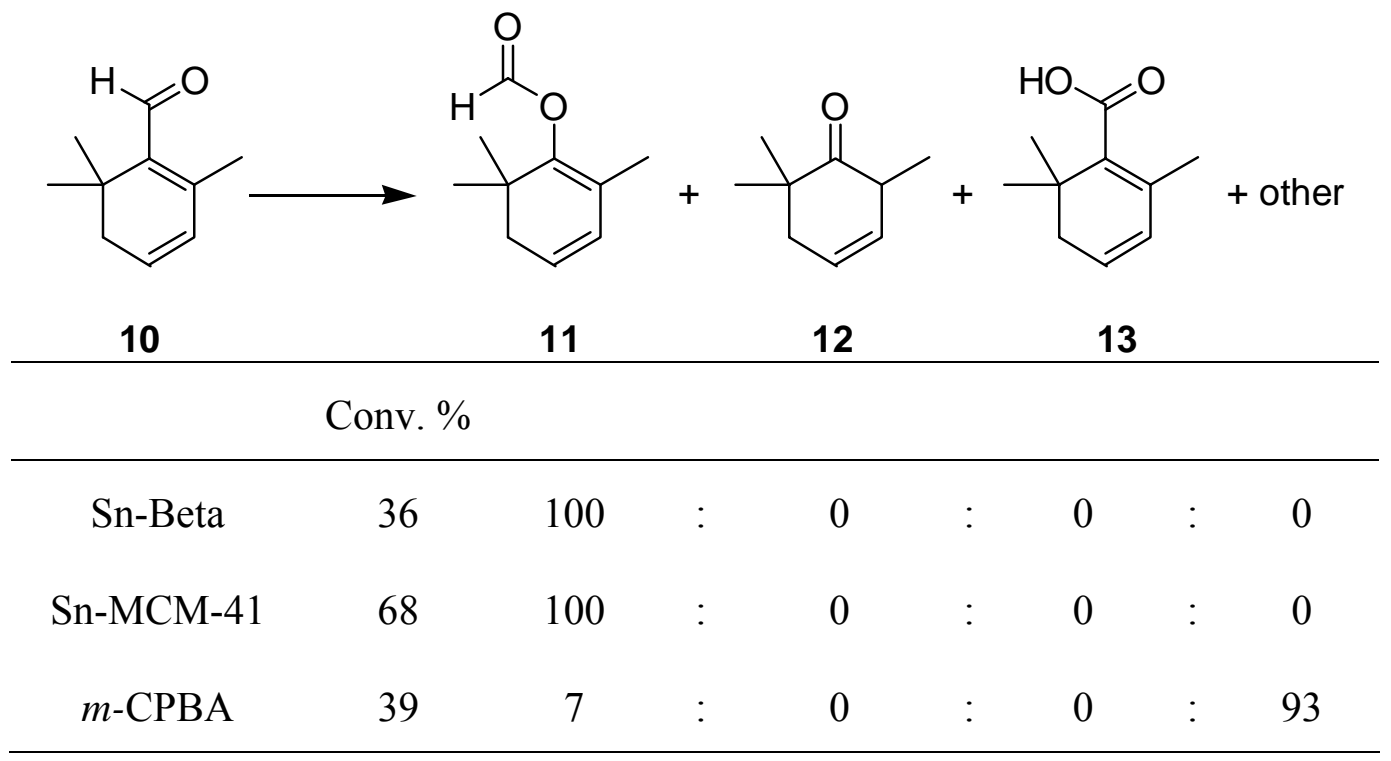

Scheme 3. Product formation in the Baeyer-Villiger oxidation of aldehyde 10. Reaction conditions: $0.5 \mathrm{~g}$ of aldehyde $\mathbf{1 0}(3.7 \mathrm{mmol}), 1.5$ equiv. of aqueous $\mathrm{H}_{2} \mathrm{O}_{2}(50 \%), 50 \mathrm{mg}$ of SnBeta, $3.0 \mathrm{~g}$ of tert.- amyl alcohol, at $100^{\circ} \mathrm{C}$. The reaction time was $1 \mathrm{~h}$ in the Sn-Beta case, and only 15 min with Sn-MCM-41 as catalyst. For the oxidation with $m$-CPBA, $0.5 \mathrm{~g}$ of the aldehyde was reacted with 1.0 equiv. of $m$-CPBA in $3.0 \mathrm{~g}$ of tert.- amyl alcohol at $100^{\circ} \mathrm{C}$ for $30 \mathrm{~min}$.

When the steric demand of the substrate was further increased by changing from a cyclic aldehyde to a bicyclic one, namely to myrtenal (14), Sn-Beta zeolite became an unsuitable catalyst. After a reaction time of $1 \mathrm{~h}$ only $10 \%$ of myrtenal (14) was converted (cf., Scheme 4) and no substantial improvement could be detected at prolonged reaction times. Additionally, the selectivity was reduced owing to the formation of significant amounts of acid $\mathbf{1 7}$ and other products. Again, better results were obtained with Sn-MCM-41 - with 40\% of aldehyde 14 having been converted after $1 \mathrm{~h}$ and the Baeyer-Villiger products obtained with $93 \%$ selectivity. Interestingly, most of the formate ester is hydrolyzed in this case into the corresponding ketone nopinone (16) which has been detected in several essential oils. The increased degree of hydrolysis can be due to a release of strain when eliminating the double bond in the ring system. Indeed, when in comparison with the carbon analogues, $\alpha$-pinene (double-bond forming part of the bicyclic ring system) and $\beta$-pinene (exo- double bond), $\alpha$-pinene can be isomerized into $\beta$ pinene with high selectivity, ${ }^{9}$ indicating that the exo- double bond is thermodynamically more 
stable. In the peracid case, the observed conversion (cf., Scheme 4) may be improved easily, but the desired products are obtained with low selectivity. The product selectivity towards formate ester $\mathbf{1 5}$ and its hydrolysis product $\mathbf{1 6}$ is decreased by the regioisomeric Baeyer-Villiger reaction product 17 , which is detected in $31 \%$ yield, and by $10 \%$ owing to epoxidation products.

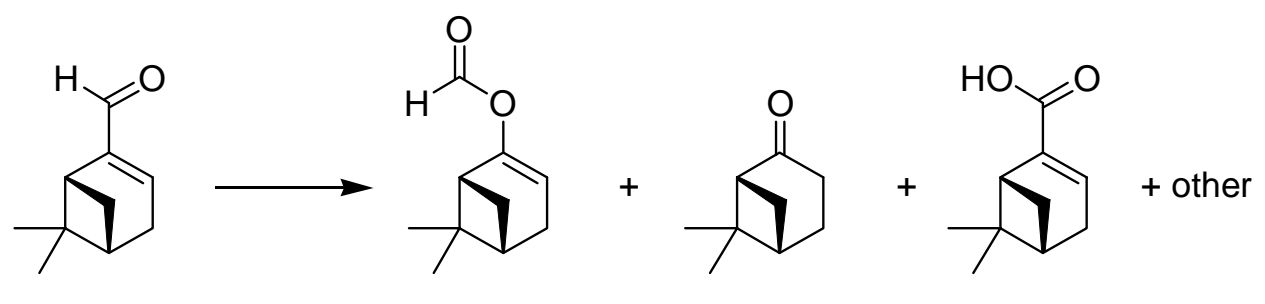

\begin{tabular}{ccccccccc}
14 & 15 & & 16 & & 17 \\
\hline & Conv. $\%$ & & & & & & & \\
\hline Sn-Beta & 10 & 67 & $:$ & 16 & $:$ & 7 & $:$ & 10 \\
Sn-MCM-41 & 40 & 19 & $:$ & 74 & $:$ & 6 & $:$ & 1 \\
$m$-CPBA & 16 & 48 & $:$ & 11 & $:$ & 31 & $:$ & 10 \\
\hline
\end{tabular}

Scheme 4. Product formation in the Baeyer-Villiger oxidation of aldehyde 14. Reaction conditions: $0.5 \mathrm{~g}$ of aldehyde 14 (3.7 mmol), 1.5 equiv. of aq. $\mathrm{H}_{2} \mathrm{O}_{2}(50 \%), 50 \mathrm{mg}$ of Sn-Beta, $3.0 \mathrm{~g}$ of tert.- amyl alcohol, reaction temperature $100{ }^{\circ} \mathrm{C}$, and $1 \mathrm{~h}$ reaction time. For the oxidation with $\mathrm{m}$-CPBA, $0.5 \mathrm{~g}$ of the aldehyde was reacted with 1.0 equiv. of $\mathrm{m}$-CPBA in $3.0 \mathrm{~g}$ of tert.amyl alcohol at $25^{\circ} \mathrm{C}$ for $1 \mathrm{~h}$.

Another interesting class of $\alpha, \beta$-unsaturated aldehydes is those with an aromatic substituent at the $\beta$-position of the double bond (Scheme 5). For the melonal synthesis from citral (3), traces have been observed of a side-product, namely 6-methyl-5-hepten-2-one (4). ${ }^{5}$ It has been proposed that this could be formed from the 2,3-epoxide after opening by hydrogen peroxide and Grob fragmentation, ${ }^{10}$ with the epoxide being formed by a Weitz-Scheffer- type of reaction, catalyzed by the Sn-Beta catalyst. It has been established by, "in-situ" IR spectroscopy that the carbonyl oxygen coordinates to the Lewis-acid tin center causing a positive partial charge at the carbon atom of the carbonyl group. Then, in the case of the $\alpha, \beta$-unsaturated aldehydes, this partial charge should be partly delocalized to the double bond ( $\beta$ position), and consequently the initial step of the Weitz-Scheffer epoxidation, i.e., a nucleophilic attack onto the double bond, should be facilitated. Nevertheless, for citral (3) this reaction is much slower than the corresponding nucleophilic attack of hydrogen peroxide onto the carbonyl carbon atom (BaeyerVilliger oxidation). Now, when cinnamaldehyde (3-phenyl-2-propenal, 18, $\mathrm{X}=\mathrm{H}$ ) or paramethoxycinnamaldehyde [3-(4-methoxyphenyl)-2-propenal], 18, $\mathrm{X}=\mathrm{MeO}$ ) are employed as substrates these epoxidation-derived by-products, benzaldehyde $(\mathbf{2 1}, \mathrm{X}=\mathrm{H})$ and 4methoxybenzaldehyde (21, $\mathrm{X}=\mathrm{MeO}$ ), are obtained with approximately $20 \%$ and $10 \%$ selectivity, respectively (Scheme 5). This increase should be due to an improved stabilization by 
the aromatic unit of the positive partial charge at the $\beta$-position of the double bond, favoring the attack of hydrogen peroxide onto the double bond at the expense of the attack on the carbonyl group.

The next interesting observation is that for both catalysts, Sn-Beta and Sn-MCM-41, the para-methoxy isomer is converted much better than the parent compound (cf., Scheme 5). This is congruent with the results on the Baeyer-Villiger oxidation of aromatic aldehydes, where the para-methoxybenzaldehyde has been converted with higher conversion than benzaldehyde. ${ }^{11}$ However, not only was the reaction rate influenced in that case, but also the product selectivity. In the oxidation of benzaldehyde, no migration of the aromatic unit has been observed and, consequently, benzoic acid was the only product. In contrast, in the present case no hydrogenatom migration is observed to yield the carboxylic acid. Clearly, the interpolated double bond determines the migration properties relative to the aromatic ring, but the activation of the molecule can be influenced by the aromatic substituents.

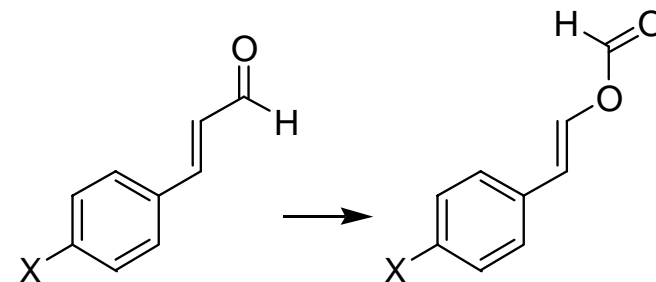

18
19

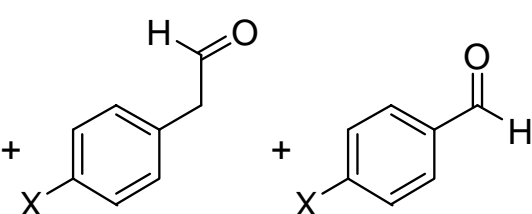

20
21

\begin{tabular}{lllllll}
\hline & & $\mathrm{t}$ & Conv. & \multicolumn{2}{c}{ Product distribution } \\
\cline { 5 - 7 } $\mathrm{X}$ & Cat & {$[\mathrm{h}]$} & {$[\%]$} & $\mathbf{1 9}$ & $\mathbf{2 0}$ & $\mathbf{2 1}$ \\
\hline $\mathrm{OMe}$ & Sn-Beta & 0.5 & 38 & 84 & 6 & 10 \\
OMe & Sn-MCM-41 & 0.5 & 48 & 69 & 18 & 13 \\
OMe & m-CPBA & 0.5 & 22 & 16 & 34 & 3 \\
$\mathrm{H}$ & Sn-Beta & 0.5 & 17 & 76 & 0 & 24 \\
$\mathrm{H}$ & Sn-MCM-41 & 0.5 & 9 & 57 & 24 & 19 \\
\hline
\end{tabular}

${ }^{\mathrm{a}}$ The missing $47 \%$ of the product mixture is the epoxide of ester 19.

Scheme 5. Product formation in the Baeyer-Villiger oxidation of aldehyde 18. Reaction conditions: $0.5 \mathrm{~g}$ of aldehyde $18(3.8 \mathrm{mmol} \mathrm{X}=\mathrm{H}, 3.4 \mathrm{mmol} \mathrm{X}=\mathrm{OMe}), 1.5$ equiv. of $50 \%$ aq. $\mathrm{H}_{2} \mathrm{O}_{2}(50 \%), 50 \mathrm{mg}$ of Sn-Beta, $3.0 \mathrm{~g}$ of tert.- amyl alcohol, reaction temperature $100{ }^{\circ} \mathrm{C}$, and $1 \mathrm{~h}$ reaction time. For the oxidation with $m$-CPBA, $0.5 \mathrm{~g}$ of the aldehyde was reacted with 1.0 equiv. of $m$-CPBA in $3.0 \mathrm{~g}$ of tert.- amyl alcohol at $25^{\circ} \mathrm{C}$.

With respect to catalytic activity, the conversion of the para-methoxy-aldehyde $\mathbf{1 8}$ is $48 \%$ with Sn-MCM-41, while for Sn-Beta 38\% is obtained. In this case, the reaction rate is limited by diffusion with Sn-Beta zeolite. Cinnamaldehyde $(\mathbf{1 8}, \mathrm{R}=\mathrm{H})$ is not activated by a methoxy group 
as is the former substrate, and with Sn-MCM-41 the conversion level dropped drastically. With Sn-Beta the decrease is smaller since the diffusion control is now replaced by rate control by the intrinsic reactivity. Consequently, as already mentioned above, in this aspect $\mathrm{Sn}$-Beta is superior to Sn-MCM-41.

Sn-MCM-41 may also be applied as catalyst for the Baeyer-Villiger oxidation of aromatic aldehydes by hydrogen peroxide. The test reaction here is the oxidation of piperonal (22) to sesamol or sesamol formate ester (23). Sesamol or its derivatives often contribute to antioxidative properties of formulations, ${ }^{12}$ and it is known as an intermediate for the production of paroxetine, which is used as an anti-depressant drug. ${ }^{13}$ Scheme 6 shows that the Sn-MCM-41 is $25 \%$ more active than Sn-Beta, which can again be attributed to the hindrance caused by the Beta network. Although the conversion is quite low, at only $25 \%$, the selectivity towards the desired product is excellent and no over-oxidation observed, so the unconverted substrate can be recovered and re-used. To achieve a higher conversion directly, Al-Beta zeolite may be used as the catalyst in this case and a $60 \%$ conversion can be obtained. This is possible since the substrate is not very prone to side-reactions, and high selectivity can be expected with many oxidants.

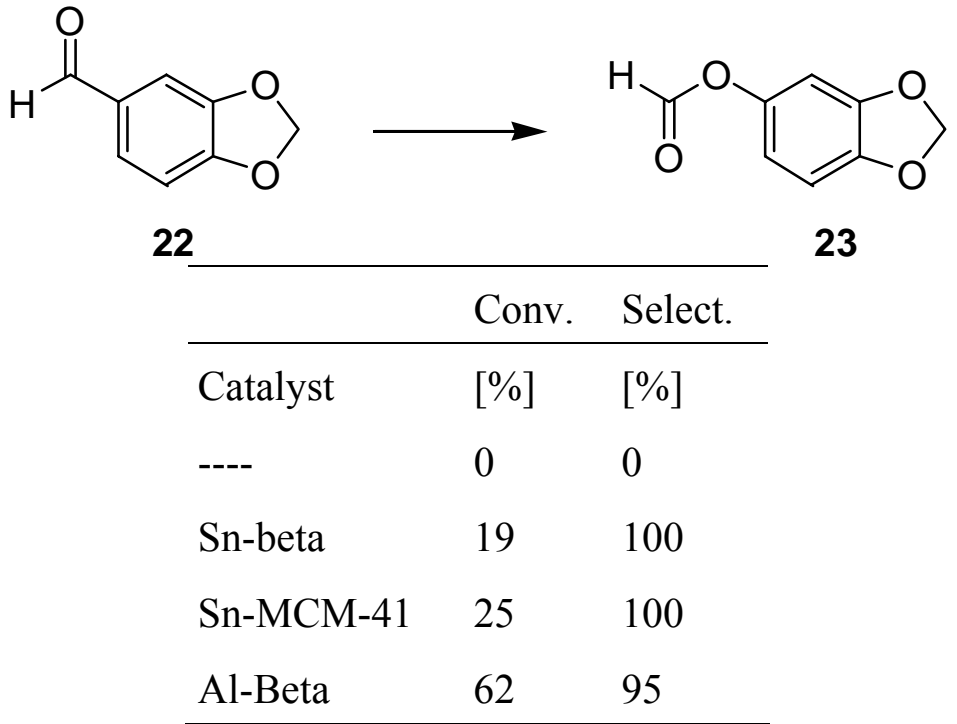

Scheme 6. Product formation in the Baeyer-Villiger oxidation of aldehyde 22. Reaction conditions: $0.5 \mathrm{~g}$ of aldehyde $22(3.3 \mathrm{mmol}), 1.5$ equiv. of $50 \%$ aq. $\mathrm{H}_{2} \mathrm{O}_{2}, 50 \mathrm{mg}$ of the catalyst, $3.0 \mathrm{~g}$ of acetonitrile, reaction temperature $80^{\circ} \mathrm{C}, 7 \mathrm{~h}$ reaction time.

In summary, we have demonstrated here by means of selected examples having industrial relevance that Sn-MCM-41 can be an interesting catalyst for Baeyer-Villiger oxidation using hydrogen peroxide as oxidant. Thus, when organic molecules are too large to diffuse well into the micropores of Sn-Beta, the mesoporous molecular sieve Sn-MCM-41 with a pore diameter of $3.5 \mathrm{~nm}$ can be a good alternative. However, when the reactants and products can diffuse, Sn-Beta is the preferred catalyst. 


\section{Experimental Section}

General Procedures. Hydrogen peroxide (50\%), aldehydes and solvents were purchased from Aldrich. GC analyses were carried out by using a HP 5890 gas chromatograph equipped with a $25 \mathrm{~m}$ HP-5 column. GC-MS analyses for the identification of products were performed on an Agilent Technologies 6890N apparatus coupled with an Agilent Mass-Selective Detector 5973 Network.

Synthesis of the molecular sieves. Sn-Beta was synthesized according to a literature procedure. ${ }^{2,14}$ The Sn-Beta zeolite was calcined at $853 \mathrm{~K}$ for $3 \mathrm{~h}$. High crystallinity of the zeolite was observed by XRD, and no peaks of $\mathrm{SnO}_{2}$ were found in the diffractogram. Nitrogen adsorption experiments on the calcined Beta samples gave an isotherm very similar to that of pure silica Beta, with values of micropore volume of $0.20-0.21 \mathrm{~cm}^{3} \mathrm{~g}^{-1}$ and BET surface areas of $450-475 \mathrm{~m}^{2} \mathrm{~g}^{-1}$. The Sn content $\left(2.0 \mathrm{wt}\right.$. \% of $\left.\mathrm{SnO}_{2}\right)$ was determined by atomic absorption. The Sn-MCM-41 sample was synthesized according the following procedure. ${ }^{8}$ An aqueous solution of hexadecyltrimethylammonium hydroxide $\left(\mathrm{C}_{16} \mathrm{TAOH}\right)$ was mixed with a tetramethylammonium hydroxide solution (25\%, Aldrich) and an aqueous solution of $\mathrm{SnCl}_{4} .5 \mathrm{H}_{2} \mathrm{O}$ (98\%, Aldrich). After homogenization, the silica (Aerosil, Degussa) was added with continuous stirring. The final composition was: $1.0 \mathrm{SiO}_{2}: 0.16 \mathrm{C}_{16} \mathrm{TAOH}: 0.26 \mathrm{TMAOH}: 0.04$ $\mathrm{SnCl}_{4}: 24.3 \mathrm{H}_{2} \mathrm{O}$. The homogeneous gel was sealed in Teflon-lined stainless steel autoclaves and heated at $135{ }^{\circ} \mathrm{C}$ under static conditions during 24 hours. The resulting solid product was recovered by filtration, washed and dried at $60{ }^{\circ} \mathrm{C}$ for 24 hours. The occluded organic was removed by heating the solid at $813 \mathrm{~K}$ for 1 hour in a flow of $\mathrm{N}_{2}$, followed by 6 hours in air. The solid obtained presents an XRD pattern typical of the MCM-41 structure (Figure 1). The Sn content $\left(9.0\right.$ wt. $\%$ of $\mathrm{SnO}_{2}$ ) was determined by atomic absorption. The mesoporous material had a BET surface area of $833 \mathrm{~m}^{2} / \mathrm{g}$, a pore volume of $0.77 \mathrm{~mL} / \mathrm{g}$ and a channel diameter of $38 \AA$.

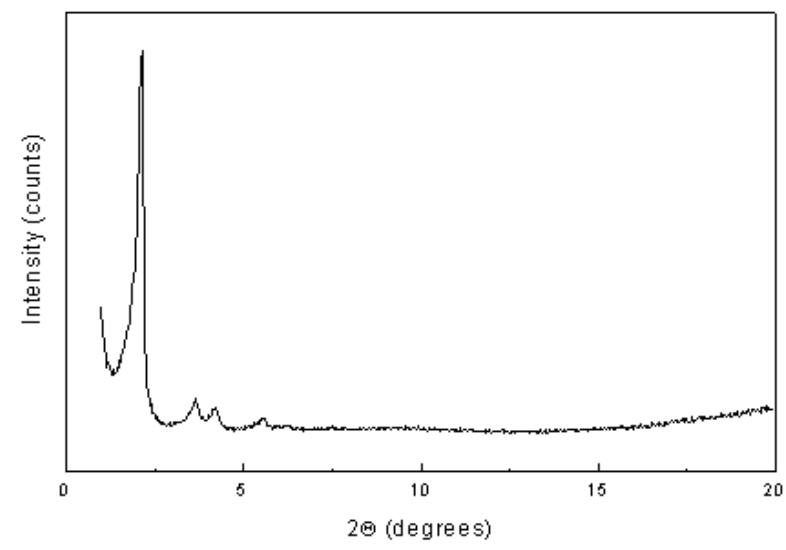

Figure 1. XRD pattern of as-prepared Sn-MCM-41. 


\section{General procedure for the Baeyer-Villiger oxidation}

The aldehyde $(0.5 \mathrm{~g})$, aqueous $\mathrm{H}_{2} \mathrm{O}_{2}(50 \%, 1.5$ equiv.), $3.0 \mathrm{~g}$ of solvent, and catalyst (normally $50 \mathrm{mg}$ ) were stirred magnetically and heated to the desired reaction temperature. The reaction was followed by gas chromatography, and the products identified by comparison with reference samples or by GC-MS spectroscopy.

\section{Acknowledgments}

The authors thank CICYT (MAT2003-07945-C02-01), and the Generalitat Valenciana for financing this work. M. R. is grateful to the Spanish Ministry of Science and Technology for a "Ramón y Cajal" Fellowship.

\section{References}

1. Corma, A.; Nemeth, L. T.; Renz, M.; Valencia, S. Nature 2001, 412, 423.

2. Renz, M.; Blasco, T.; Corma, A.; Fornés, V.; Jensen, R.; Nemeth, L. Chem. Eur. J. 2002, 8, 4708.

3. Corma, A.; Iborra, S.; Mifsud, M.; Renz, M.; Susarte, M. Adv. Synth. Catal. 2004, 346, 257.

4. Bauer, K.; Garbe, D.; Suburg, H. Common Fragrance and Flavor Materials, Wiley-VCH: Weinheim, 1997; p 149f.

5. Corma, A.; Iborra, S.; Mifsud, M.; Renz, M. Chem. Commun., submitted.

6. G. R. Krow Org. React. 1993, 43, 251.

7. Renz, M.; Meunier, B.; Eur. J. Org. Chem. 1999, 737.

8. Corma, A.; Navarro, M. T.; Nemeth, L.; Renz, M. Chem. Commun. 2001, 2190.

9. Bauer, K.; Garbe, D.; Suburg, H. Common Fragrance and Flavor Materials, Wiley-VCH: Weinheim, 1997; p 49.

10. Adam, W.; Corma, A.; Martinez, A.; Renz, M. Chem. Ber. 1996, 129, 1453.

11. Corma, A.; Fornés, V.; Iborra, S.; Mifsud, M.; Renz, M. J. Catal. 2004, 221, 67.

12. Chen, X.; Ahn, D. U. J. Am. Oil Chem. Soc. 1998, 75, 1717.

13. Kuo, L. H. Lin, C.-D.; Jwo, C.-D.; Lin, L.-L.; Lee, S.-L.; Tsai, S.-J. US Patent Appln. 2002123655, 2002.

14. Valencia, S.; Corma, A. US Patent 5968473 (assigned to UOP), 1999. 